\title{
Older People Quality of Life Evaluation
}

\author{
Eris Dhamo (PhD Student) \\ Department of Social Work and Social Policy, Faculty of Social Science \\ University of Tirana, Albania \\ eris_dhamo@yahoo.com,

\section{Dr. Doc. Nevila Koçollari (Furxhiu)} \\ Department of Social Work and Social Policy, Faculty of Social Science \\ University of Tirana, Albania \\ nkocollari@gmail.com
}

Doi:10.5901/mjss.2014.v5n13p385

\section{Abstract}

Lately world well-known problem, ageing population is starting to turn into an issue for our country, Albania, as Europe is dealing with it years go. In Albania the number of elderly is increasing by about $2 \%$ per year and the various culture and social problems facing society are burdening elderly situation. Changes from one regime to another are accompanied with change of life rhythm, change of family structure, culture differences and perception on how thinks should be. This study has its main focus on testing elderly quality of live in Tirana, as a forgoing study assessing the quality of life of older people across the Albania country. Quality of life of older people in Tirana result low and this brings the need for more attention to the elderly issue. Orientations of all academics and policymakers are focusing towards identifying effective elements and mechanisms to improve the situation of the elderly.

Keywords: elderly, quality of life, Tirana.

\section{Introduction}

Old age comprises "the later part of life; the period of life after youth and middle age . . ., usually with reference to deterioration. When old age begins cannot be universally defined because it shifts according to the context. The United Nations has agreed that $60+$ years may be usually denoted as old age, and this is the first attempt at an international definition of old age. However, for Africa, the World Health Organization set 50 as the beginning of old age that because the general socio-cultural and demographic context is a determination element for conceptual stratification. At the same time, the WHO recognized that the developing world often defines old age, not by years, but by new roles, loss of previous roles, or inability to make active contribution to society. Most developed Western countries set the age of 60 to 65 for retirement and old-age social programs eligibility. However, various countries and societies reckon the onset of old age as anywhere from the mid-40s to the 70s. Furthermore, the fact that life expectancy beyond 80 has become widespread has shifted definitions of old age. For this study we have been referred for old age those persons who are $65+$ years. In Albania portion of old people is increasing rapidly with a percentage of nearly 2 a year. According to the last census (2011) 9.8\% of Albanian resident population meets the age requirement and in Tirana there are 76705 persons $65+$ from 749365 in total (that's nearly the same portion with that of total population). According to the Albanian National Statistics Progressions actually perceptual of elderly people is nearly $13 \%$.

The ageing process is, of course, a biological reality which has its own dynamic, largely beyond human control. However, it is also subject to the constructions by which each society makes sense of old age. In the developed world, chronological time plays a paramount role. The age of 60 or 65 years, roughly equivalent to retirement ages in most developed countries, is said to be the beginning of old age. In many parts of the developing world, chronological time has little or no importance in the meaning of old age. Other socially constructed meanings of age are more significant, such as the roles assigned to older people; in some cases it is the loss of roles accompanying physical decline which are significant in defining old age. Gerontologists in many studies have recognized the very different conditions that people experience as they grow older within the years defined as old age. In the United States, most people in their 60s and 70s are in the best shape they have known. However, by their 80s most of these people will become frail, a condition marked by serious mental and physical debilitation.

That why, some gerontologists have recognized the diversity of old age by defining sub-groups. One study 
distinguishes the young old (60 to 69), the middle old (70 to 79), and the very old (80+) (Rockwood K, Mitnitski A 2011). Another study's sub-grouping is young-old (65 to 74), middle-old (75-84), and oldest-old (85+) (Tsai SY, Chi LY, Lee Ch, Chou P. 2007). A third sub-grouping is "young old" (65-74), "old" (74-84), and "old-old" (85+) (Otero-Rodriguez A, Leon-Munoz LM, Balboa-Castillo T, Banegas JR, Rodriguez-Artalejo F, Guallar-Castillon P 2010).

Old age comprises the four dimensions: chronological, biological, psychological, and social (M asel MC, Ostir GV, Ottenbacher KJ 2010). Chronological age may differ considerably from a person's functional age. The distinguishing marks of old age normally occur in all five senses at different times and different rates for different persons (Bowling $A$ 2009). In addition to chronological age, people can be considered old because of the other three dimensions of old age. For example, people may be considered old when they become grandparents or when they begin to do less or different work in retirement (Bowling A, Stenner P 2011).

Quality of life (QOL) is the general well-being of individuals and societies. QOL has a wide range of contexts, including the fields of international development, healthcare, and politics. Quality of life should not be confused with the concept of standard of living, which is based primarily on income. Instead, standard indicators of the quality of life include not only wealth and employment but also the built environment, physical and mental health, education, recreation and leisure time, and social belonging. According to ecological economist Robert Costanza: While Quality of Life (QOL) has long been an explicit or implicit policy goal, adequate definition and measurement have been elusive. Diverse "objective" and "subjective" indicators across a range of disciplines and scales, and recent work on subjective well-being (SWB) surveys and the psychology of happiness have spurred renewed interest.

Also frequently related are concepts such as freedom, human rights, and happiness. However, since happiness is subjective and difficult to measure, other measures are generally given priority. It has also been shown that happiness, as much as it can be measured, does not necessarily increase correspondingly with the comfort that results from increasing income. As a result, standard of living should not be taken to be a measure of happiness. Also sometimes considered related is the concept of human security, though the latter may be considered at a more basic level and for all people.

\section{Methods}

We carried out a study with 120 persons aged $65+, 20$ of which were even been part of a semi interview. The mean age of sample was 74 (56 \% women, $44 \%$ man) .years and the study take place in Tirana, the capital city of Albania. According to Official Data, Census 2011, 749365 was Tirana resident population, from which 25187 was 65-59 years old (12 616 Male and 12571 Female);22 305 was 70-74 years old (10 879 Male and 11426 Female); 15570 was 75-79 years old ( 7453 Male and 8117 Female); 8561 was 80-84 years old ( 3742 Male and 4816 Female); 3532 was 85-89 years old (1 364 Male and 2168 Female); and 1550 was 90+ years old (496 Male and 1054 Female). The population female domination can be sees after 70's.

The overall aim of the study was to contribute to the development of a conceptual framework and body of knowledge on quality of life in old age based on older people's views. For the realization of this study are used semistructured interviews with 20 elderly with different social living situations and application of OPQOL 35 , which was evaluated as highly reliable qualified instrument for elderly quality of life. OPQOL came as face to face interview with 120 persons aged $65+$, chosen randomly. In fact it was used an exclusion criteria for seniors who weren't able to understand, to communicate or for those with mentally ill. The follow-up semi structured interviews about quality of life were carried out at same day or a day later. The aim was to interview a broad cross-section of respondents to the survey to obtain a better understanding of people's. Data were collected by the studies with the help of a small trained group of students. All subjects who participated in this study gave their informed consent.

The OPQOL questionnaire consists of 35 statements with the participant being asked to indicate the extent to which he/she agrees with every single statement by choosing one of five possible options among "strongly disagree", "disagree", "neither agree nor disagree", "agree" and "strongly agree". Each of the five possible answers is given a score of 1 to 5 so that higher scores indicate a better QOL. Thus the total score ranges from 35 (the worst possible QOL) to 175 (the best possible QOL). The 35 statements of the questionnaire consider the following aspects of QOL: life overall, health (score range 4-20), social relationships and participation, independence, control over life and freedom, home and neighborhood, psychological and emotional well-being, financial circumstances, leisure, activities and religion. Interviews too were structured on the same way to understand better if there was any element that mainly interfere and change their perception on quality of life.

Interviews of Quality of life were organized as non-structured questionnaire with 5 non-inductive questions and open answers. Answers were written down and later categorized and analyzed. Subjects were asked: 1a) How would you describe the life you are currently living? 1b) Why would you say that? 2) What in your current life is well? 3) What in your 
current life is not well? 4) What could happen to make your life better than now? and 5) What could happen in your life to make it worse than now.

From one study of older people

Table 1: Older people's definitions of the constituents of quality of life

\begin{tabular}{|c|c|c|c|c|c|c|}
\hline \multirow[b]{2}{*}{ Constituent } & \multicolumn{2}{|c|}{$\begin{array}{l}\text { Good things that } \\
\text { give life quality }\end{array}$} & \multicolumn{2}{|c|}{$\begin{array}{l}\text { Bad things that take } \\
\text { guality away from lives }\end{array}$} & \multicolumn{2}{|c|}{$\begin{array}{l}\text { Mentioned } \\
\text { good or bad }\end{array}$} \\
\hline & $\%$ & $\mathrm{~N}$ & $\%$ & $\mathrm{~N}$ & $\%$ & $\mathrm{~N}$ \\
\hline Social relationships & 96 & $(77)$ & 80 & $(64)$ & 99 & (79) \\
\hline Home and neighborhoods & 96 & (77) & 84 & $(67)$ & 100 & $(80)$ \\
\hline Psychological wellbeing & 96 & (77) & 63 & $(50)$ & 99 & (79) \\
\hline Other activities done alone & 93 & (74) & - & $(0)$ & 93 & (74) \\
\hline Health & 85 & $(68)$ & 83 & $(66)$ & 99 & (79) \\
\hline Social roles and activities & 80 & $(64)$ & 1 & (1) & 80 & (64) \\
\hline Financial circumstances & 73 & $(58)$ & 53 & (42) & 91 & (73) \\
\hline Independence & 69 & $(55)$ & 46 & (37) & 84 & (67) \\
\hline Other/miscellaneous & 18 & (14) & 19 & (15) & 31 & (25) \\
\hline Society/politics & 1 & (1) & 43 & (34) & 43 & (34) \\
\hline Number of respondents & & $(80)$ & & $(80)$ & & $(80)$ \\
\hline
\end{tabular}

Source: Bowling et al. (in press).International Journal of Aging and Human Development.

\section{Analysis}

The data are analysis on two ways. The OPQOL questionnaires were analyses with SPSS data analyze program. All the questions of interviews were analyses with NVivo, an computer assisted qualitative analysis. The researchers were attended to organize comparisons between subjects and scoring in the quartiles of these indices and the rest of the sample were performed by means of the chi-squared test or Fisher's exact test. Furthermore, unilabiate logistic regression analyses were conducted; all of them assuming the specific outcome as dependent variable and the OPQOL total score as the independent variable.

The QOL of the participants was evaluated by means of the OPQOL questionnaire, which has been validated in a multiethnic community-dwelling older population in England. Cronbach's alpha coefficient for the Italian outpatient population enrolled in this study was found to be 0.78 , i.e. above the 0.70 threshold of acceptability for internal consistency. Moreover, this questionnaire was recently shown not only to have excellent applicability to cognitively normal subjects but also to be applicable to people suffering from different disease. In two studies addressing the association of QOL with both frailty status and living status in an older population referred to the same geriatric service in Italy. The OPQOL questionnaire consists of 35 statements with the participant being asked to indicate the extent to which he/she agrees with every single statement by choosing one of five possible options among "strongly disagree", "disagree", "neither agree nor disagree", "agree" and "strongly agree". Each of the five possible answers is given a score of 1 to 5 so that higher scores indicate a better QOL. Thus the total score ranges from 35 (the worst possible QOL) to 175 (the best possible QOL). The 35 statements of the questionnaire consider the following aspects of QOL: life overall, health (score range 4-20), social relationships and participation, independence, control over life and freedom, home and neighborhood, psychological and emotional well-being, financial circumstances, leisure, activities and religion.

\section{Results}

In fact perceptions on quality of life were quite low. Tirana elderly people have more expectations on how their life should be. As it can be seen (from the Table 1) below there are gender differences on elderly perception on quality of life as a whole, even that the difference isn't statistically important (chi-square; $p=0.37$ ) it can be seen that woman are more likely to rate quality of life as bad (chi-square; $p=0.053$ ). Only $22.5 \%$ of the studied subjects (or 27 out of 120 ) defined their current quality of life with positive assessments, while $50 \%$ (60/120) had a negative assessment of their current quality of life, that means that twice of subjects have bad perceptions of their quality of life. A percentage of $27.5 \%(33 / 120)$ of them had a neutral assessment. 
Table 2: Older people rate of quality of life as a whole

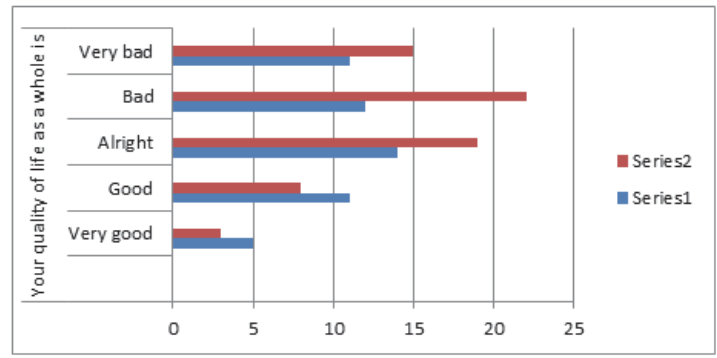

What is a good quality of life:

A good quality of life for them was a good health situation in most of cases; financial security, but not the one they were paid, as all the subject were having pension and good relationship in general, with family member and with society as a whole. "..We aren't looking for big thinks. We are pleased with small, but secure future income that can fulfill every day's needs". They remember the time when they were young and the way they interact with elderly in society. "...No one knows respect now days. But thanks God we are with arms and legs (this is Albanian way for saying that people are healthy egnaf to fulfill whatever they need) and we are capable to manage ouerself. We can't trust or even worst cant relies to no one. Even our children don't have time to show respect, so..."

Another important issue they mention is relationship, with familiar and non-familiar persons. Having energy and capability to meet friends, to visit relatives to walk and take part in outdoor activities are another aspect that seniors evaluate as important to improve quality of life. But even this need many, at last for transportation, as it's hard for them to use public transportation (regular bus lines not always pass nearby their home or place they need to go; or they doesn't have all necessary facilities for elderly).

A debate discussion on quality of life is control over live, independence and freedom that aren't discussing theme by interviews. No one of the seniors has mention this aspect regarding improving quality of live. Independence of doing activity of daily living wasn't mention as a important aspect, as literature view refers. Pleasure of controlling themselves activity isn't mention too. Maybe because for Albanian elderly freedom refers to political status more than everyday independence.

What is a bad quality of life:

A bad quality of life was absence of capability for everyday activities, absence of family members and income and the absence of dignity, which was mention from all the subjects. They consider policymakers as incompetent to take into count the dignity for all that hard time of period they worked to build Albania. They consider the way which Albanian society treats them as absence of dignity. "...You can see the absence of respect for the elderly everywhere. On bus station, on shops, on family, everywhere you can easy find case when an elderly is maltreat. The way young act today is totally different the way we used to act when we were at their age".

The elderly complain a lot for the life they have lived till now and for the low opportunities to better that. All of them continue to talk about the time when they were young (during dictator regime), the difficulties of the everyday life, hard work, and ............... It was easy for studies to find out the pessimist situation that elderly predict. "Now we are old and don't have nothing. A pension that isn't even for paying bills, no one ask how we feel and what we think, family members that never have engnaf time to talk with us, policymakers that mention our names and our situation only during election time". The main think that make them feel bad is financial situation even that they have worked a lot their pension payment is the lowers; Pensions average is 140 USD and as can be imagine without family help the elderly can't effort living.

The main concern for them is financial situation, which influence socio-economic situation in total. Their monthly earns which came from pension aren't sufficient for expenses on physicians and medications, as public expenditure doesn't supply a range of analysis and medical services they need. It's time to say that in Albania doesn't exist gerontology specialist and such situation complicate their daily needs; as seniors now had to schedule meeting to several specialist to conclude to a diagnose.

A debate discussion on quality of life is even psychological and emotional well-being, with is another non evaluating issue from seniors. Elderly Albanian persons doesn't evaluate emotional situation as an important element which influence a lot quality of life. The way they feel on everyday life makes difference on dealing with different activities. 
And from this point of view, such as even literature refers psychological situation isn't specified, or at last mention form seniors to be important element on quality of life.

\section{Conclusions}

As expected monthly financial income was main concern but other elements as special respect and missing dignity from known and unknown was another interesting finding. The average age of sample was 74 ( $56 \%$ women, $44 \%$ man).

Quality of life of older people in Tirana is low and this brings the need for more attention to the elderly as an integral part of society. Identification of specific elements that impact more on quality of life may facilitate the design of interventions with programs dedicated reference needs.

The elderly complain a lot for the life they have lived till now and for the low opportunities to better that. All of them continue to talk about the time when they were young (during dictator regime), the difficulties of the everyday life, hard work, and ............... It was easy for studies to find out the pessimist situation that elderly predict. "Now we are old and don't have nothing. A pension that isn't even for paying bills, no one ask how we feel and what we think, family members that never have eghnaf time to talk with us, policymakers that mention our names and our situation only during election time". The main think that make them feel bad is financial situation even that they have worked a lot their pension payment is the lowers; Pensions average is 140 USD and as can be imagine without family help the elderly can't effort living.

\section{References}

"WHO"[http://www.who.int/healthinfo/survey/agei ngdefnolder/en/ "Definition of an older or elderly person"].

"Frailty in Older Adults" at http://jama.jamanetwork.com/article.aspx?articleid=204046. Accessed December 3, 2013.

"Indicators for the Minimum Data Set Project on Ageing,"http://www.who.int/healthinfo/survey/ageing_mds_report_en_daressalaam.pdf.

"Middle age begins at 55 years, survey suggests" athttp://www.bbc.co.uk/news/education-19622330. Accessed December 27, 2013.

"Old age starts at 54 (and youth ends at 32) - that's if you ask young people" athttp://www.dailymail.co.uk/news/article-2086030/Old-agestarts-54-youth-ends-32.html. Accessed 27 December 2013.

"Total Water Intakes of Community-Living Middle-Old and Oldest-Old Adults" athttp://www.ncbi.nlm.nih.gov/pmc/articles/PMC2657166/ http://transgenerational.org/aging/demographics.htm.

"When Does Someone Attain Old Age?" at http://ohioline.osu.edu/ss-fact/0101.html. Accessed November 20, 2013.

Bowling A, Grundy E: Differentials in mortality up to 20 years after baseline interview among older people in East London and Essex. Age Ageing 2009, 38:51-55. PubMed Abstract | Publisher Full Text

Bowling A, Stenner P: Which measure of quality of life performs best in older age? A comparison of the OPQOL, CASP-19 and WHOQOL-OLD.

Costanza, R. et. al. (2008) "An Integrative Approach to Quality of Life Measurement, Research, and Policy". S.A.P.I.EN.S. 1 (1)

Fernández-Ballesteros R. 1997. Quality of life: concept and assessment. In: J Adair, D Belanger, K Dion, editors. Advances in Psychological Science. Vol I: Social, Personal and Cultural Aspects. Psychological Press.

Forman DE, Berman AD, McCabe CH, Baim DS, Wei JY, "PTCA in the Elderly: the 'young-old' versus the 'old-old" athttp://www.ncbi.nlm.nih.gov/pubmed/1727842.

Forman DE, Berman AD, McCabe CH, Baim DS, Wei JY, "PTCA in the Elderly: the 'young-old' versus the 'old-old"' athttp://www.ncbi.nlm.nih.gov/pubmed/1727842.

From Reference \#8: Gorman M. Development and the rights of older people. In: Randel J, et al., eds. The ageing and development report: poverty, independence and the world's older people. London, Earthscan Publications Ltd.,1999:3-21.

Gregory, Derek; Johnston, Ron; Pratt, Geraldine; Watts, Michael; Whatmore, Sarah, eds. (June 2009). "Quality of Life". Dictionary of Human Geography (5th ed.). Oxford: Wiley-Blackwell. ISBN 978-1-4051-3287-9. http://www.britannica.com/EBchecked/topic 1426737/old-age http://www.who.int/healthinfo/survey/ageingdefnolder/en/ (Accessed December 24, 2013.

Laura E. Berk, Development Through the Lifespan, (Allyn \& Bacon, 2010), 607.

Layard, Richard (6 April 2006). Happiness: Lessons from a New Science. London: Penguin. ISBN 978-0-14-101690-0.

Lehr U. 1993. A model of well-being in old age and its consequences for further longitudinal studies. In: JJF Schroots, editor. Aging, health and competence. p. 293-302.

Martha Nussbaum and Amartya Sen, ed. (1993). The Quality of Life, Oxford: Clarendon Press. Description and and chapterpreview links.

Masel MC, Ostir GV, Ottenbacher KJ: Frailty, mortality, and health-related quality of life in older Mexican Americans.

Otero-Rodriguez A, León-Muñoz LM, Balboa-Castillo T, Banegas JR, Rodriguez-Artalejo F, Guallar-Castillón P. 2010. Change in Healthrelated quality of life as a predictor or mortality in the older adults. Quality of Life Research 19:15-23.

Pew Research Center, "Growing Old in America: Expectations vs. Reality,"http://www.pewsocialtrends.org/files/2010/10/Getting-Old-inAmerica.pdf

Phillips, Judith, Kristine Ajrouch, and Sarah Hillcoat-Nallétamby, Key Concepts in Social Gerontology (SAGE Publications, 2010), 12-13. 
Rockwood K, Mitnitski A: Frailty defined by deficit accumulation and geriatric medicine defined by frailty.

The Robert N. Butler Columbia Aging Center, "About Us."http://www.mailman.columbia.edu/academic-departments/centers/columbiaaging/about-us.(accessed December 24, 2013.

The Whoqol group. The world health organization quality of life assessment (WHOQOL): position paper from the world health organization. Soc Sci Med 1995;41(10):1403-9.

Victor G. Cicirelli, Older Adults' Views on Death (Springer, 2002), 4. 